\title{
In Search of Autism Biomarkers: Possible Autism Bio-Markers Discovery at Autism Research and Treatment Center, King Saud University, KSA
}

\author{
Dost M Halepoto and Laila Y. Al-Ayadhi
}

\begin{abstract}
Autism is a neurodevelopmental disorder, currently affecting as many as 1 out of 91 individuals in the United States; and Saudi Arabia is no exception. Autism is characterized by impairments in social interaction, difficulty with communication, and restrictive and repetitive behaviors. Although there is no known unique cause of autism, there is growing evidence that autism can be caused by a variety of factors, however its exact pathophysiology is unknown. The use of potential biomarkers that point to specific mechanism of autism disorder will help to diagnosis and tailor treatment or prevention strategies for autism rather than solely to a symptom category. The aim of this article is to provide an overview of the various potential autism biomarkers reported in literature for Saudi autistic children, particularly at Autism research and treatment center, King Saud University, KSA and consider the future development of this area of research.
\end{abstract}

Index Terms-Autism spectrum disorder, biomarkers.

\section{INTRODUCTION}

Autism is a severe neurodevelopmental disorder which involves social withdrawal, communication deficits, and stereotypic/repetitive behavior [1]. Leo Kanner initially described 'early infantile autism' in a case series in 1943, naming the disorder on the basis of the 'autistic aloneness' that he observed in his patients [2]. The pathophysiological etiologies which precipitate autism symptoms remain elusive and controversial in many cases, but both genetic and environmental factors (and their interactions) have been implicated. While autism is considered multicausal, environmental factors have received significant attention.

The prevalence of autism spectrum disorder (ASD) has increased dramatically in the past few decades [3]. The current prevalence in the United States is estimated, at 1 in 91 children [4]. Recent epidemiological studies, conducted in different regions of the world, have indicated that at least one

Manuscript received January 6, 2014; revised March 14, 2014. This work was supported by Autism Research and Treatment Centre, Al-Amodi Autism research chair, King Abdul Aziz city for science and technology (KACST), and Health Research Studies program at (NPST), at Kind Saud University, Riyadh, KSA.

Dost Muhammad Halepoto is with KSU-Autism Research and Treatment Center (99), Al-Amodi Autism research chair, Department of physiology (29), Faculty of Medicine, King Saud University, P O Box 2925, Riyadh 1146 Saudi Arabia (e-mail: dr_m_halepota@yahoo.com; tel.: 0096614699350; fax: 00966146993349).

Laila Y. Al-Ayadhi is with Autism Research and Treatment Centre (99), Al-Amodi Autism research chair, Department of physiology (29), Faculty of Medicine, King Khalid University Hospital King Saud University, PO Box, 2925, Riyadh 11461, Kingdom of Saudi Arabia (e-mail: ayadh2@ gmail.com tel.: 009661479246; fax: 00966146993349). in every 100 people has some form of autism [5].

Few reports have been published about the occurrence of autism in developing countries. Studies from the Middle East on this topic have been particularly rare [6]. Autism in Saudi Arabia is slightly higher than reported in developed countries. One report estimated that in Saudi Arabia there were 42,500 confirmed cases of autism in 2002 and that many more remained undiagnosed [7].

Although there is no known unique cause of autism, there is growing evidence that autism can be caused by a variety of disorders, however its exact pathophysiology is unknown [8] and no disease markers for the diagnosis of autism have been validated.

A reliable biomarker, however, could significantly contribute to an early and more exact autism diagnosis, a crucial prerequisite for an early behavior modifying therapeutic intervention. Furthermore, a diagnosis at an early stage could contribute to developing better coping strategies within families confronted with classical autism features of a child's behavior.

Discovery of such biomarkers may eventually lead to something like a blood test for autism, which not only would allow earlier and potentially more reliable diagnoses of autism, but would also help researchers achieve an understanding of the biological basis of the disorder. Biomarkers can be used not only to diagnose whether an individual has autism, but can also be related to particular characteristics or end phenotypes of autism [9].

The first biomarker described in ASD was elevated whole blood 5-HT, or hyper-serotonemia, identified 50 years ago [10] and unique to autism among developmental disorders [11].

Biomarkers are pharmacological and physiological measurements, or specific biochemicals in the body, that have a particular molecular feature that makes them useful for measuring the progress of disease or the effects of treatment. First, by providing sensitive and selective clinical correlates for the valuation and diagnosis of those affected by neurological disorders. Second, by providing insights into disease mechanisms that can be used to identify therapeutic targets and to develop efficacious compounds to target them.

A naïve expectation is that single biomarkers can capture the complex process underlying an illness. Rather, by looking as perturbations of biochemical networks (systems view); it becomes clear that a multiparameter analysis (panel of markers or multiple metabolites) may provide better insight into disease diagnosis, prognosis, and treatment [12]. By surveying for global changes in metabolic pathways, metabolomics-based approaches are more likely to provide a 
wealth of information that may be difficult to capture by looking at only one pathway or one biomarker.

Classical research (pre-metabolomics) on the identification of biochemical biomarkers in blood and cerebrospinal fluid (CSF) for neurological disorders has been aimed at assaying single metabolites. Often this search has been based on research hypotheses. Unfortunately, none of the single biomarkers identified to date have the desired sensitivity and specificity for diagnosis or have sufficient power to identify disorders at an early stage [13].

There are four basic challenges to biomarker identification in neurological disease are: 1) the availability of tissue at the site of pathology; 2) poor clinical diagnostics and extent of disease progression at the time of diagnosis; 3) the complexity of the brain and tissue heterogeneity; and 4) the lack of functional endpoints and models for validation [14].

\section{Possible Autism Biomarkers In SAUdi AutistiC CHILDREN}

Table I listed all possible Biomarkers reported in literature for Saudi Arabian autistic children.

TABLE. I: POSSIBLE AUTISM BIOMARKERS IN SAUDI AUTISTIC CHILDREN

\begin{tabular}{|c|c|c|c|c|c|}
\hline Biomarker & Source & Method & Increase & Decrease & Ref. \\
\hline $\begin{array}{l}\text { Proinflammatory Cytokins } \\
\text { TNFa,IL1\& IL6 }\end{array}$ & S & ELISA & $\checkmark$ & & [15] \\
\hline Oxytocin and Asopressin & $P$ & ELISA & & $\checkmark$ & [16] \\
\hline $\begin{array}{l}\text { Glycolytic enzymes } \\
\text { Lactate, Lactate oxidase } \\
\text { Pyruvate kinase, } \\
\text { Hexokinase }\end{array}$ & $\mathrm{P}$ & ELISA & $\checkmark$ & $\checkmark$ & {$[17]$} \\
\hline $\begin{array}{c}\text { Brain-Derived } \\
\text { Neurotrophic Factor (BDNF) }\end{array}$ & $\mathrm{S}$ & ELISA & & $\checkmark$ & [18] \\
\hline Desert Hedgehog (DHH) & $\mathrm{S}$ & ELISA & & $\checkmark$ & [19] \\
\hline $\begin{array}{l}\text { Indian Hedgehog } \\
(\mathrm{IHH})\end{array}$ & $\mathrm{S}$ & ELISA & $\checkmark$ & & [20] \\
\hline $\begin{array}{c}\text { Neurokinin A and } \\
\text { anti-ribosomal P protein }\end{array}$ & $\mathrm{S}$ & ELISA & $\checkmark$ & & [21] \\
\hline Progranulin & $P$ & ELISA & & $\checkmark$ & {$[22]$} \\
\hline $\begin{array}{l}\text { Serotonin, Anti-myelin } \\
\text { basic protein }\end{array}$ & $\mathrm{S}$ & ELISA & $\checkmark$ & & {$[23]$} \\
\hline Osteopontin & $\mathrm{S}$ & ELISA & $\checkmark$ & & {$[24]$} \\
\hline Anti-ganglioside M1 & $\mathrm{S}$ & ELISA & $\checkmark$ & & {$[25]$} \\
\hline $\begin{array}{l}\text { S100B protein and } \\
\text { antiribosomal } \mathrm{P}\end{array}$ & $\mathrm{S}$ & ELISA & $\checkmark$ & & [26] \\
\hline $\begin{array}{c}\text { Vascular endothelial } \\
\text { growth factor (VEGF), } \\
\text { Platelet-derived growth factor } \\
\text { (PDGF) }\end{array}$ & $\mathrm{P}$ & - & $\begin{array}{r}\text { No } \\
\text { Change } \\
\checkmark\end{array}$ & & [27] \\
\hline Interleukin-17A & $\mathrm{S}$ & ELISA & $\checkmark$ & & {$[28]$} \\
\hline $\begin{array}{l}\text { Thymus and } \\
\text { activation-regulated } \\
\text { chemokine (TARC). } \\
\text { Macrophage-derived } \\
\text { chemokine (MDC) }\end{array}$ & S & $\begin{array}{c}\text { Quantitative } \\
\text { sandwich enzyme } \\
\text { immunoassay } \\
\text { technique }\end{array}$ & $\checkmark$ & & [29] \\
\hline $\begin{array}{l}\text { Prostaglandin E2 (PGE2), } \\
\text { Leukotriene, } \\
\text { Isoprostane }\end{array}$ & $\mathrm{P}$ & ELISA & $\checkmark$ & & [30] \\
\hline
\end{tabular}

ELISA $=$ (Enzyme-linked immunosorbent assay) 


\section{RESUlTS AND DisCUSSION}

In search of biomarker discovery at autism research and treatment center, King Saud University several proteins, hormones and enzymes in blood samples have been proposed as autism biomarkers in autistic Saudi children (Table I).

Furthermore metabolic biomarkers related to energy metabolism in Saudi autistic children were also reported [31]. Higher activities of $\mathrm{Na}^{+} / \mathrm{K}^{+}$ATPase and $\mathrm{CK}$ in plasma of autistic patients were recorded which proved the impairment of energy metabolism in these children compared to age and sex matching healthy controls. ADPase was found significantly higher in autistic patients while ATPase was non-significantly elevated compared to control. In spite of the significant increase of $\mathrm{Na}+\mathrm{K}+\mathrm{ATPase}$ activity in autistic patients, there was no significant difference observed in the levels of ATP, ADP, and AMP in both groups. Study confirmed the impairment of energy metabolism in Saudi autistic patients which could be correlated to the oxidative stress previously recorded [32] in the same investigated samples.

The role of detoxification in the etiology of autism, selected parameters/ metabolic biomarkers related to sulfur-dependent detoxification mechanisms in plasma of autistic children from Saudi Arabia was investigated [33]. Results indicated Reduced glutathione, total glutathione, GSH/GSSG and activity levels of GST were significantly lower, GR shows non-significant differences, while, Trx, TrxR and both Prx I and III recorded a remarkably higher values in autistics compared to control subjects.

Al-Gadani et al. [34] measured oxidative stress and antioxidant-related parameters/metabolic biomarkers (enzymatic and non-enzymatic) in 30 Saudi autistic children. Levels of lipid peroxides, vitamin E, vitamin C, glutathione together with enzymatic activities of glutathione peroxidase (GSH-Px), and catalase were determined in plasma while superoxide dismutase (SOD was measured in red blood cells of both groups.

Lipid peroxidation was found to be significantly higher in autistic compared to control Saudi children. On the other hand, vitamin $\mathrm{E}$ and glutathione were remarkably lower in autistic patients while vitamin $\mathrm{C}$ shows non-significant lower values. Regarding the enzymatic antioxidants, both glutathione peroxidase (GSH-Px) and superoxide dismutase (SOD) were significantly higher in autistic compared to control while catalase recorded more or less similar activities in both groups.

$\mathrm{Na}^{+}, \mathrm{K}^{+}, \mathrm{Ca}^{2+}, \mathrm{Mg}^{2+}, \mathrm{Na}^{+} / \mathrm{K}^{+}, \mathrm{Ca}^{2+} / \mathrm{Mg}^{2+}$ together with IL6, $\mathrm{TNFa}$ as proinflammatory cytokines and caspase3 as proapoptotic biomarker were determined [35] in plasma of 25 Saudi autistic male patients and compared to 16 age and gender matching control samples.

The data obtained showed that Saudi autistic patients have a remarkable lower plasma caspase $3, \mathrm{IL} 6, \mathrm{TNFa}, \mathrm{Ca}^{+}$and a significantly higher $\mathrm{K}^{+}$compared to age and gender matching controls. On the other hand both $\mathrm{Mg}^{2+}$ and $\mathrm{Na}^{+}$were non-significantly altered in autistic patients. Pearson correlations revealed that plasma concentrations of the measured cytokines and caspase- 3 were positively correlated with $\mathrm{Ca}^{2+}$ and $\mathrm{Ca}^{2+} / \mathrm{K}^{+}$ratio.

Alteration of the selected measured ions confirms that oxidative stress and defective mitochondrial energy production could be contributed in the pathogenesis of autism. Moreover, it highlights the relationship between the measured ions, IL6, TNFa and caspase 3 as a set of signaling pathways that might have a role in generating this increasingly prevalent disorder.

Same group [36] considered fatty acids as diagnostic markers and proved that fatty acids were altered in the plasma of autistic patients, specifically showing an increase in most of the saturated fatty acids except for propionic acid, and a decrease in most of polyunsaturated fatty acids compared to age -matching controls.

The altered fatty acid profile was discussed in relation to oxidative stress, mitochondrial dysfunction and the high lead $(\mathrm{Pb})$ concentration previously reported in Saudi autistic patients [34]. Results could reflect the high degree of specificity and sensitivity of the altered fatty acids as biomarkers in autistic patients from Saudi Arabia.

Biological marker (biomarker) is an indicator of a biological state. Biomarkers need to be measurable, associated with the particular condition and stable or predictable across and within individuals. Biomarkers can be measured using various biological samples, including blood, urine or saliva. There is increased interest among researchers in so-called neuromarkers, which are biomarkers based on measures of neurochemicals in the cerebrospinal fluid, brain structure measured using MRI, and/or brain function. Biomarkers have several applications. First, they can be viewed as risk factors that increase an individual's susceptibility for a condition, and as such can be used to identify individuals who are at high risk for the condition. Biomarkers that can be detected before disease symptoms occur could be used to improve early detection of a condition. Second, they can be used to improve diagnosis, as they may enable better prediction of the nature and severity of disease outcomes in an individual. Third, they may be used to develop personalized treatments and, if monitored over time, can be used to evaluate treatment outcomes. A wide range of autism biomarkers has been proposed, but as of yet none has been validated for clinical use.

There is an intensive search for biological markers for autism. Such biomarkers could not only reveal causes of the condition but could also be clinically useful in complementing or improving the behavioral diagnosis of autism and in enabling earlier detection of the condition. Biomarkers would thereby assist in the validation of very early, targeted and individualized intervention programmers.

However, a number of key scientific challenges have yet to be overcome. First, experience in other areas of biomedical research highlights how challenging it can be to translate biomarker discovery into clinical applications, and very few clinically useful biomarkers have as yet been identified for neuropsychiatric conditions.

Second, the identification of autism biomarkers has so far proved elusive, partly because definitions of the condition itself have changed considerably over time and are still developing.

Third, developmentally invariant biomarkers for autism are particularly challenging because the phenotypic manifestations unfold as development progresses, especially 
during infancy and early childhood, reflecting dynamic developmental interactions among multiple risk factors ${ }_{[3]}$

Fourth, several proposed biomarkers were found not to be universal, and none has indexed the presence of autism in a majority of cases (poor sensitivity). Candidate biomarkers tend also to be associated with a range of other neurodevelopmental conditions and not only with autism.

Finally, measuring some putative biomarkers is currently expensive, laborious and reliant on a high degree of technical expertise, restricting the possibility of their application in most clinical settings.

Although autism is defined on the basis of behavioral criteria, the condition is associated with a wide range of other biological phenomena. It is hoped that translating markers of these phenomena into clinically useful biomarkers will improve the validity and efficiency of existing diagnostic methods. Currently, the diagnostic process typically includes a clinical developmental history, assessments of speech, language and intellectual abilities, and of educational or vocational attainment. Standardized and semi-standardized procedures for conducting developmental interviews with caregivers and for observing and assessing social, communicative and repetitive behaviors that are characteristic of autism have been developed to aid and improve clinical diagnosis [38].

It has been suggested that biomarkers may aid and/or improve the efficiency of the diagnostic process, and recent studies [39], [40] have attempted to build diagnostic algorithms for autism on the basis of composite features of brain structure that have been associated with the condition. It is hoped that valid biomarkers that are identified before the onset of clear symptoms will help in the early detection of emerging autism.

There is a long tradition of biomarker research in Autism spectrum disorder (ASD). Biomarkers may point toward ASD susceptibility factors in different ways. In theory, a biomarker could contribute directly to susceptibility, but a biomarker also may represent an endophenotype, or a heritable trait resulting from an underlying factor that is the prime contributor to ASD susceptibility [41]. Finally, a biomarker may be a secondary result of ASD itself or of ASD treatment. Deciding among these possibilities has therapeutic relevance in narrowing down potential targets and/or using the particular measure as a diagnostic or treatment aid. Structural neuroimaging studies have also sought to identify biomarkers of autism [42].

Peripheral biomarkers related to the immune system have also generated considerable interest. Whereas evidence suggests that there may be altered immune system function in some children with ASD, the specific alterations appear to vary across studies and will require further analysis to reach consensus [43]. Autism biomarkers were identified that could be categorized according to the key theories that exist regarding the etiology of autism: gastrointestinal factors, immune dysregulation, heavy metal toxicity, neurotransmitter abnormalities, and oxidative stress.

\section{CONCLUSION}

Autism is a neurodevelopmental disorder. An increasing prevalence of Autism shows the importance of several biomarkers in the disease diagnosis and treatment. Alterations in neurotransmitters, oxidative damage, neuroinflammation, mitochondrial dysfunction, neurological abnormalities in brain and gastrointestinal disturbances play a promising in the pathology of disease. Periodic diagnosis of these biomarkers in biological samples will provide a basement for effective and efficient therapy.

Biomarkers should ideally be quantitative biological measures with an accurate indication of a specific mechanism and ideally are not invasive. Identifying biomarkers will almost certainly lead to a better understanding of the pathogenesis required to design the most effective treatments of autism. There is widespread hope that the possible discovery of valid biomarkers for autism will both reveal the causes of autism and enable earlier and more targeted methods for diagnosis and intervention.

Collaborative approaches involving scientists and other stakeholders must combine the search for valid, clinically useful autism biomarkers with efforts to ensure that individuals with autism and their families are treated with respect and understanding.

\section{ACKNOWLEDGMENT}

We thank Autism Research and Treatment Centre, Al-Amodi Autism research chair, King Abdul Aziz city for science and technology (KACST), and Health Research Studies program at (NPST), at Kind Saud University for sponsor and financial support.

\section{REFERENCES}

[1] American Psychiatric Association, "Diagnostic and statistical manual of mental disorders," Tech. Rep. DSM-IV-TR, American Psychiatric Association, Washington, DC, USA, 2000.

[2] L. Kanner, "Autistic disturbances of affective contact," Nerv Child, vol. 2, pp. 217-50, 1943.

[3] S. W. Scherer and G. Dawson, "Risk factors for autism: translating genomic discoveries into diagnostics," Hum Genet, vol. 130, pp. 123-148, 2011.

[4] M. D. Kogan, S. J. Blumberg, L. A. Schieve, C. A. Boyle, J. M. Perrin, R. M. Ghandour et al., "Prevalence of parent-reported diagnosis of autism spectrum disorder among children in the US 2007," Pediatrics, vol. 124, pp. 1395-140, 2009.

[5] Y. S. Kim, B. L. Leventhal, Y. J. Koh, E. Fombonne, E. Laska, E. C. Lim et al., "Prevalence of autism spectrum disorders in a total population sample," Am. J. Psychiatry, vol. 168, pp. 904-912, 2011.

[6] M. M. Afifi, "Mental health publications from the Arab world," Eastern Mediterranean Health Journal, vol. 1, no. 3, pp. 319-328, 2005.

[7] S. M. Al-Salehi, E. H. Al-Hifthy, and M. Ghaziuddin, "Autism in Saudi Arabia: presentation, clinical correlates and comorbidity," Transcult Psychiatry, vol. 46, no. 2, pp. 340-347, 2009.

[8] G. Trottier, L. Srivastava, and C. D. Walker, "Etiology of infantile autism: a review of recent advances in genetic and neurobiological research," J Psychiatry Neurosci, vol. 24, pp. 103-115, 1999.

[9] Autismspeaks. [Online]. Available: http://www.autismspeaks.org/science/science_news/imfar_2009_final _recap.php.

[10] R. J. Schain and D. X. Freedman, "Studies on 5-hydroxyindole metabolism in autistic and other mentally retarded children," J Pediatr, vol. 58, pp. 315-320, 1961.

[11] H. G. Hanley, S. M. Stahl, and D. X. Freedman, "Hyperserotoninemia and amino metabolites in autistic and retarted children," Arch Gen Psychiatry, no. 34, pp. 521-531, 1977.

[12] L. Hood, J. R. Heath, M. E. Phelps, and B. Lin, "System's biology and new technologies enable predictive and preventative medicine," Science, vol. 306, pp. 640-643, 2004.

[13] A. El-Ansary, S. Al-Daihan, A. Al-Dbass, and L. Al-Ayadhi, "Measurement of selected ions related to oxidative stress and energy 
metabolism in Saudi autistic children," Clin Biochem., vol. 43, no. 1-2, pp. 63-70, Jan. 2010.

[14] T. Dunckley, D. K. D. Coon, and A. D. Stephan, "Discovery and development of biomarkers of neurological disease," Drug Discov Today, vol. 10, no. 5, pp. 326-334, March 2005.

[15] L. Al-Ayadhi, "Pro-inflammatory cytokines in autistic children in central Saudi Arabia," Neurosciences (Riyadh), vol. 10, no. 2, pp 155-158, April 2005.

[16] L. Al-Ayadhi, "Altered oxytocin and vasopressin levels in autistic children in Central Saudi Arabia," Neurosciences, vol. 10, no. 1, pp. 47-50, 2005 .

[17] A. El-Ansary et al., "Activities of key glycolytic enzymes in the plasma of Saudi autistic patients," Journal of Clinical Trials, vol. 2 pp. 49-57, 2010.

[18] L. Al-Ayadhi, "Serum Levels of Brain-Derived Neurotrophic Factor (BDNF) in Autistic Children in Central Saudi Arabia," Conference Proceedings Journal, vol. 2, pp. 36-40, 2011

[19] S. Bashir, D. M. Halepoto, and L. Al-Ayadhi, "Serum Level of Desert Hedgehog Protein in Autism Spectrum Disorder: Preliminary Results," Med Princ Pract, Aug. 2013.

[20] S. Bashir and L. AL-Ayadhi, "Indian Hedgehog Protein Levels in Autistic Children: Preliminary Results," J Mol Biomark Diagn, vol. 3 , no. 6, 2012.

[21] G. A Mostafa and L. Y. AL-Ayadhi, "The possible link between the elevated serum levels of neurokinin A and anti-ribosomal $\mathrm{P}$ protein antibodies in children with autism," Neuroinflammation, vol. 8, no. 180 2011.

[22] L. Y. AL-Ayadhi1 and G. A Mostafa, "Low plasma progranulin levels in children with autism," Journal of Neuroinflammation, vol. 8, no. 111, Sep. 2011.

[23] G. A. Mostafa and L. Y. AL-Ayadhi, "A lack of association between hyperserotonemia and the increased frequency of serum anti-myelin basic protein auto-antibodies in autistic children," Journal of Neuroinflammation, vol. 8, no. 71, June 2011.

[24] L. Y. Al-Ayadhi and G. A. Mostafa, "Increased serum osteopontin levels in autistic children: relation to the disease severity," Brain Behav Immun, vol. 25, pp. 1393-1398, 2011

[25] G. A Mostafa and L. Y AL-Ayadhi, "Increased serum levels of anti-ganglioside M1 auto-antibodies in autistic children: relation to the disease severity," Journal of Neuroinflammation, vol. 8, no. 39, 2011.

[26] L. Y. Al-Ayadhi and G. A. Mostafa, "A lack of association between elevated serum levels of S100B protein and autoimmunity in autistic children," Journal of Neuroinflammation, vol. 9, no. 54, March 2012.

[27] F. A. Zakareia, L. Y. Al-Ayadhi, and A. A. Al-Drees, "Study of dual angiogenic/neurogenic growth factors among Saudi autistic children and their correlation with the severity of this disorder," Neurosciences (Riyadh), vol. 17, no. 3, pp. 213-218, July 2012.

[28] L. Y. Al-Ayadhi and G. A. Mostafa, "Elevated serum levels of interleukin-17A in children with autism," J. Neuroinflammation, vol. 9, no. 158, July 2012.

[29] L. Y. Al-Ayadhi and G. A. Mostafa, "Elevated serum levels of macrophage-derived chemokine and thymus and activation-regulated chemokine in autistic children," J Neuroinflammation, vol. 10, no.72, June 2013.

[30] A. El-Ansary and L. Al-Ayadhi, "Lipid mediators in plasma of autism spectrum disorders," Lipids Health Dis, vol. 11, no. 160, Nov. 2012.

[31] O. A. Al-Mosalem, A. El-Ansary, O. Attas, and L. Al-Ayadhi, "Metabolic biomarkers related to energy metabolism in Saudi autistic children," Clinical Biochemistry, vol. 42, pp. 949-957, 2009.

[32] L. Y. Al-Ayadhi, "Oxidative stress and neurodegenerative disease," Neurosciences (Riyadh), vol. 9, no. 1, pp. 19-23, 2004.

[33] Y. A. Al-Yafee, L. Y. Al- Ayadhi, S. H. Haq, and A. K. El-Ansary, "Novel metabolic biomarkers related to sulfur-dependent detoxification pathways in autistic patients of Saudi Arabia," BMC Neurology, vo. 11, no. 139, Nov. 2011.

[34] Y. Al-Gadani, A. El-Ansary, O. Attas, and L. Al-Ayadhi, "Metabolic biomarkers related to oxidative stress and antioxidant status in Saudi autistic children," Clinical Biochemistry, vol. 42, pp. 1032-1040, 2009.
[35] A. K. El-Ansary, A. G. Ben Bacha, and L. Y Al-Ayadhi, "Proinflammatory and proapoptotic markers in relation to mono and di-cations in plasma of autistic patients from Saudi Arabia," Journal of Neuroinflammation, vol. 8, no. 142, 2011.

[36] A. K El-Ansary, A. G Ben Bacha, and L. Y Al- Ayahdi, "Plasma fatty acids as diagnostic markers in autistic patients from Saudi Arabia," Lipids in Health and Disease, vol. 10, no. 62, 2011.

[37] M. Elsabbagh and M. H. Johnson, "Getting answers from babies about autism," Trends Cogn. Sci., vol. 14, pp. 81-87, 2010.

[38] C. P. Johnson and S. M. Myers, "dentification and evaluation of children with autism spectrum disorders," Pediatrics, vol. 120, pp. $1183-1215,2000$.

[39] Y. Jiao, R. Chen, X. Ke, K. Chu, Z. Lu, and E. H. Herskovits, "Predictive models of autism spectrum disorder based on brain regional cortical thickness," Neuroimage, vol. 50, pp. 589-599, 2010.

[40] E. Christine, A. Marquand, J. Mourão-Miranda, P. Johnston, E. M. Daly, M. J. Brammer et al., "Describing the brain in autism in five dimensions - magnetic resonance imaging-assisted diagnosis of autism spectrum disorder using a multiparameter classification approach," $J$ Neurosci, vol. 30, pp. 10612-10623, 2010.

[41] I. I. Gottesman and T. D. Gould, "The endophenotype concept in psychiatry: etymology and strategic intentions," Am J Psychiatry, vol. 160, pp. 636-645, 2003.

[42] J. V.-V. Weele and R. D. Blakely, "Networking in Autism: Leveraging Genetic, Biomarker and Model System Findings in the Search for New Treatments," Neuropsychopharmacology, vol. 37, no. 1, pp. 196-212, Jan 2012.

[43] M. Careaga, J. Van de Water, and P. Ashwood, "Immune dysfunction in autism: a pathway to treatment," Neurotherapeutics, vol. 7, pp. 283-292, 2010.

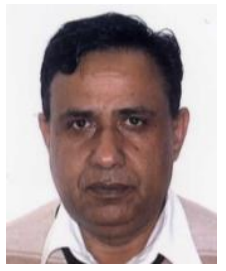

Dost Muhammad Halepoto is a Ph.D. Currently he is an associate professor in Autism Research and Treatment center, Al-Amodi Autism research chair, Department of physiology (29), Faculty of Medicine, King Saud University, Riyadh, Saudi Arabia.

In 1990, he obtained his Ph.D. in Chemistry from University of Surrey, Guildford, UK. In 1976, he received his M.Sc. in chemistry, from University of Sindh at Jamshoro, Sindh, Pakistan. In 1975, he received his BSc (Hons) in chemistry from University of Sindh, Pakistan.

He has three recent publications: 1) S. Bashir, D.M. Halepoto and L.Y. AL-Ayadhi. "Serum level of desert hedgehog protein in autistic spectrum disorder: preliminary results," Med Princ Pract, August, 2013. 2) L. Y AL-Ayadhi and D.M. Halepoto, "A Review: Role of Proteomics in the Discovery of Autism Biomarkers," J Coll Physicians Surg Pak, vol.23, no. 2, pp. 137-143, Feb 2013. 3) D. M. Halepoto, S. Bashir and L. Y. AL-Ayadhi, "Discovery and Development of Autism Biomarkers: The State of the Science," International Conference on Innovations in Medical Sciences (ICICEMS'2012) at Dubai, UAE on 27-28 Dec 2012.

Laila Y. Al-Ayadhi is a BBMC, $\mathrm{MB} \mathrm{ChB}, \mathrm{PhD}$ and professor of neurophysiology and the director of Autism Research and Treatment Centre (99), Al-Amodi Autism research chair, Department of physiology (29), Faculty of Medicine, King Khalid University Hospital King Saud University, PO Box, 2925, Riyadh 11461, Kingdom of Saudi Arabia. In 1999 she obtained her Ph.D in neurophysiology from Leicester University, England, UK. In 1992 she obtained MB ChB from Glasgow University, Scotland, UK. In 1988 she received BBMS from Kuwait University, Kuwait. She has three recent publications: 1) L. Y. Al-Ayadhi, N.E. Elamin, "Camel Milk as a Potential Therapy as an Antioxidant in Autism Spectrum Disorder (ASD)," Evidence-Based Complementary and Alternative Medicine, August 2013, Article ID 602834. 2, L. Y. Al- Ayadhi, G. A. Mostafa, "Elevated serum levels of macrophage-derived chemokine and thymus and activation-regulated chemokine in autistic children," $J$ Neuroinflammation, vol. 10, no. 72, June 2013, 3) L. Al-Ayadhi, D.M. Halepoto, "Role of proteomics in the discovery of autism biomarkers," J Coll Physicians Surg Pak, vol. 23, no.2, pp. 137-143, Feb 2013. 